\title{
Avaliação em casa de vegetação do uso de sorgo, milheto e crotalária no manejo de Meloidogyne javanica
}

\author{
Mário M. Inomoto ${ }^{1}$, Sonia R. Antedomênico ${ }^{1}$, Viviane P. Santos ${ }^{1}$, Rosangela A. Silva ${ }^{2}$ \& Giovane C. Almeida ${ }^{1}$ \\ ${ }^{1}$ Departamento de Entomologia, Fitopatologia e Zoologia Agrícola, ESALQ, Universidade de São Paulo, Cx. Postal 09, \\ 13418-900, Piracicaba, SP, Brasil; ${ }^{2}$ Grupo de Produção Acadêmica, Ciências Agrárias e Biológicas, Univag - Centro \\ Universitário, 78118-000, Várzea Grande, MT, Brasil
}

Autor para correspondência: Mário M. Inomoto, e-mail: mminomot@esalq.usp.br

\begin{abstract}
RESUMO
A rotação de cultura pode desempenhar um importante papel no manejo de nematóides fitoparasitos, dependendo da disponibilidade de culturas econômicas que lhes sejam não hospedeiras ou más hospedeiras. Como alternativa, culturas de cobertura ou adubos verdes podem ser utilizados em sucessão com as culturas econômicas de verão. O objetivo do presente estudo foi avaliar, em casa de vegetação, a reação de híbridos e cultivares comerciais de sorgos (Sorghum bicolor) granífero e silageiro ao nematóide Meloidogyne javanica, e estimar seu efeito na população do nematóide, em comparação ao milheto (Pennisetum glaucum; mau hospedeiro), Crotalaria spectabilis e $C$. juncea, não hospedeiras. Com base em dois experimentos comparando diversos híbridos e cultivares de sorgo, estabeleceu-se que, como regra geral, o sorgo granífero é mau hospedeiro e o silageiro, bom hospedeiro de $M$. javanica; porém o sorgo silageiro 'BRS 601' foi exceção. Em outros experimentos, o sorgo granífero, o milheto 'BN 2', Crotalaria spectabilis 'Comum' e C. juncea 'IAC-KR-1' reduziram a densidade de M. javanica no solo e os sorgos silageiros aumentaram.

Palavras-chave: Crotalaria juncea, Crotalaria spectabilis, Pennisetum glaucum, Sorghum bicolor, rotação de cultura, nematóide-dasgalhas.
\end{abstract}

\begin{abstract}
Greenhouse evaluation of the potential of sorghum, pearl millet and crotalaria in the management of Meloidogyne javanica

Crop rotation can play a valuable role in managing plant parasitic nematodes, depending on the availability of profitable non-host or poor host crops. Alternatively, non-host cover crops or green manures can be used in succession to summer cash crops for this purpose. The aim of the current study was to evaluate, under greenhouse conditions, the host status of commercial hybrids and cultivars of grain and silage sorghum (Sorghum bicolor) for Meloidogyne javanica, and to assess the effect of sorghum on nematode population in comparison with pearl millet (poor host for M. javanica), showy crotalaria and sunn hemp (both non-hosts). Based on two experiments, it was stated that, as a rule, grain sorghum is a poor host for M. javanica, but silage sorghum is a good host. Silage sorghum 'BRS 601' was an exception. In other experiments, grain sorghum, pearl millet (Pennisetum glaucum 'BN 2'), showy crotalaria (Crotalaria spectabilis 'Comum') and sunn hemp (C. juncea 'IAC-KR-1') reduced M. javanica population level, while silage sorghum increased the nematode density.
\end{abstract}

Keywords: Crotalaria juncea, Crotalaria spectabilis, Pennisetum glaucum, Sorghum bicolor, crop rotation, root knot nematode.

\section{INTRODUÇ̃̃O}

Três espécies de nematóides das galhas causam perdas relevantes em culturas anuais no Brasil: Meloidogyne incognita (Kofoid \& White, 1919) Chitwood, 1949, M. arenaria (Neal, 1889) Chitwood, 1949 e M. javanica (Treub, 1885) Chitwood, 1949, considerada a mais importante, pelas perdas causadas em extensas áreas cultivadas com soja (Glycine max) no Norte do Rio Grande do Sul, Sudoeste e Norte do Paraná, Sul de São Paulo e principalmente no Brasil central (região do cerrado), nos estados do Mato Grosso, Mato Grosso do Sul, Goiás, Piauí, Maranhão e Bahia (Silva et al., 2001; Castro et al., 2003). O manejo de M. javanica em soja pode ser feito pelo uso de cultivares resistentes ou tolerantes, mas esses estão disponíveis em pequeno número (Silva, 1998). Em áreas nas quais a soja é cultivada sob sistema de plantio direto (SPD), o manejo de M. javanica poderia ter como um dos componentes o uso de culturas de coberturas não hospedeiras ou más hospedeiras, como o milheto 'BN 2' (Pennisetum glaucum R.Br.) (Asmus \& Andrade, 1998). Porém, outros genótipos de milheto, como 'BRS 1501', assim como as principais culturas de coberturas em uso no Brasil, são hospedeiras moderadamente a altamente favoráveis a $M$. javanica (Inomoto et al., 2005).

Outras opções para o manejo de áreas infestadas são as crotalárias e o sorgo [Sorghum bicolor (L.) Moench]. Crotalaria spectabilis Roth, C. breviflora DC. e C. juncea L. são plantas valiosas no manejo dos nematóides das galhas, embora não perfeitamente adaptadas ao SPD, por serem plantas em geral cultivadas como adubos verdes na primavera ou verão (Santos \& Ruano, 1987; Tanaka et al., 1992, 
Wang et al., 2002; Inomoto et al., 2006). No Sul do Brasil, o sorgo granífero (Sorghum bicolor) é cultivado no verão, mas na região do cerrado é uma típica "cultura de safrinha", ou seja, plantada em sucessão às culturas de verão. Atualmente, a expressão econômica da referida cultura é pequena, mas pode crescer em futuro próximo, especialmente em regiões com temperaturas elevadas e chuvas escassas, pois tolera precipitações inferiores a $600 \mathrm{~mm}$ anuais (Santos, 2003). Nos Estados Unidos, o sorgo granífero é utilizado para rotação com soja em áreas infestadas com os nematóides das galhas, pois os genótipos disponíveis são maus hospedeiros de $M$. arenaria, M. incognita e M. javanica (Rich \& Kinloch, 2007a, b). No Brasil não há informações sobre o uso do sorgo granífero para o manejo de $M$. javanica. Em testes de casa de vegetação, o sorgo silageiro 'IPA 7301011' propiciou maiores aumentos populacionais, com fatores de reprodução entre 27,81 e 39,57 para populações de M. javanica do Mato Grosso do Sul e de São Paulo (Inomoto et al., 2005). Logo, há indícios de que o sorgo silageiro e o granífero, embora pertencentes à mesma espécie botânica, apresentam reações diversas a $M$. javanica.

Assim, há opções viáveis para o manejo de $M$. javanica, embora dependente da resolução de algumas questões importantes, com destaque para a provável variação genética do sorgo e do milheto em relação à reprodução do nematóide. Dentro do quadro apresentado, o presente trabalho foi realizado tendo como objetivos testar a reação do sorgo a M. javanica e avaliar, em condições controladas, o potencial de sorgo, milheto e crotalária no manejo do nematóide.

\section{MATERIAL E MÉTODOS}

Foram conduzidos quatro experimentos em casa de vegetação na Escola Superior de Agricultura "Luiz de Queiroz" (ESALQ/USP - 2242'S, 47³8'W, 546 m alt.), com temperatura média do solo variável entre $18^{\circ} \mathrm{C}$ (em junho) e $28^{\circ} \mathrm{C}$ (em dezembro).

\section{Substrato e inóculo}

Nos experimentos 1 e 3 utilizou-se substrato com $76 \%$ de areia, $6 \%$ de silte, $18 \%$ de argila, pH 5,6 e 1,1\% de matéria orgânica. Para os experimentos 2 e 4, preparou-se substrato com $57 \%$ de areia, $4 \%$ de silte, $39 \%$ de argila, $\mathrm{pH}$ 6,3 e 1,5\% de matéria orgânica. Pelo menos quatro semanas antes de serem utilizados nos experimentos, os substratos foram autoclavados a $121^{\circ} \mathrm{C}$ por 2 horas.

A população de Meloidogyne javanica utilizada nos experimentos 1, 2 e 4 foi originária do município de Júlio de Castilhos RS, a partir de massas de ovos retiradas de raízes de soja. No experimento 3, utilizou-se população proveniente de tubérculos de batata coletados no município de Pereiras SP. Nos dois casos, o nematóide foi multiplicado em casa de vegetação, alternadamente em plantas de fumo (Nicotiana tabacum), soja e tomateiro (Lycopersicon esculentum). Para a identificação específica das populações, foram feitas preparações microscópicas da região perineal das fêmeas (Hartman \& Sasser, 1985), comparando-se com as descrições disponíveis (Taylor \& Sasser, 1978; Kleynhans, 1986).

Os inóculos (ovos e $\mathrm{J}_{2}$ ) dos experimentos 1, 2 e 3 foram preparados a partir das raízes de tomateiro, processadas pelo método do liquidificador e centrífuga (Coolen \& D'Herde, 1972 ), com uso de hipoclorito de sódio $(\mathrm{NaOCl})$ a $0,5 \%$. $\mathrm{O}$ inóculo do experimento 4 constituiu-se de substrato infestado a partir da sua mistura com raízes de sorgo e soja parasitadas pelo nematóide. Para sua obtenção, sorgo e soja foram semeadas diretamente em copos plásticos de $480 \mathrm{~cm}^{3}$ (7,2 cm de diâmetro e 11,8 de altura) contendo $400 \mathrm{~cm}^{3} \mathrm{de}$ substrato desinfestado. Após a germinação, o substrato foi infestado com 1.000 ovos e $\mathrm{J}_{2}$ por copo. Depois de onze semanas, as raízes foram desintegradas em liquidificador e misturadas ao substrato dentro de tanque de cerâmica com capacidade de 50 litros, onde o material foi mantido por três semanas.

\section{Experimentos 1 e 2}

No experimento 1, de novembro de 2003 a janeiro de 2004, os tratamentos foram sete genótipos de sorgo, Crotalaria spectabilis (planta não hospedeira de $M$.javanica) e soja cultivar 'Pintado' (planta hospedeira de M. javanica). Três dos sorgos foram híbridos intra-específicos do tipo granífero (A, B e C - híbridos não identificados por questão de sigilo comercial) e quatro do tipo silageiro (D - híbrido não identificado por questão de sigilo comercial; BRS 601, BRS 700 e BRS 701). As plantas foram obtidas pela semeadura direta em copos plásticos de $480 \mathrm{~cm}^{3}$ contendo $400 \mathrm{~cm}^{3}$ de substrato. $\mathrm{O}$ delineamento experimental foi inteiramente ao acaso com nove tratamentos e cinco repetições. Oito dias após a semeadura, realizou-se desbaste para três plântulas por repetição (copo); quatro dias após o desbaste, o substrato foi infestado com 3.000 nematóides (ovos e $\mathrm{J}_{2}$ ) em dois orifícios a $1 \mathrm{~cm}$ das plantas, um com $2 \mathrm{~cm}$ de profundidade e outro com $4 \mathrm{~cm}$.

A avaliação foi realizada aos 51-53 dias após a inoculação. Os nematóides foram extraídos das raízes pelo método do liquidificador, peneiramento e centrifugação (Coolen \& D'Herde, 1972), com uso de hipoclorito de sódio $(\mathrm{NaOCl})$ a $1,0 \%$, e a população final (Pf) estimada pela contagem em lâminas de Peters, utilizando-se microscópio óptico. Após a contagem foram calculados os fatores de reprodução do nematóide (FR) em cada parcela. Os dados foram submetidos à análise de variância, após terem sido normalizados pela transformação para $\ln (x+1)$, e as médias comparadas por meio do teste de Tukey a $5 \%$ de probabilidade de erro.

O experimento 2 foi realizado entre os meses de março e junho de 2005, com metodologia semelhante ao 1 , porém com menor população inicial do nematóide $(\mathrm{Pi}=$ 1.000 ovos e $\mathrm{J}_{2}$ ), a inclusão de mais uma planta hospedeira (soja 'Conquista') e cinco genótipos de sorgo, a cultivar IPA 7301011 (silageiro) e os híbridos BR 304, Dow 740, Dow 741 e Dow 822 (graníferos). Por ter sido realizado em época menos quente que o experimento 1 , e portanto provavelmente em condições menos favoráveis a $M$. 
javanica (Taylor \& Sasser, 1978), optou-se por aumentar a duração do período experimental pós-inoculação para 7780 dias. A análise estatística foi realizada conforme descrito para o experimento 1 .

\section{Experimento 3}

Neste experimento foram comparadas duas espécies de crotalárias, $C$. juncea e $C$. spectabilis, consideradas não hospedeiras de M. javanica (Santos \& Ruano, 1987), com sorgo silageiro (IPA 7301011) - hospedeiro favorável e milheto (BRS 1501) - moderadamente favorável (Inomoto et al., 2005), em relação à reprodução do nematóide. A semeadura foi direta em seis copos plásticos de $480 \mathrm{~cm}^{3}$ contendo $400 \mathrm{~cm}^{3}$ de substrato. Após o desbaste, deixando três plântulas por copo, o substrato foi infestado com 1.000 ovos e $\mathrm{J}_{2}$. Como testemunha, incluíram-se parcelas em que o substrato foi infestado, mantido sem plantas e irrigado diariamente, à maneira de alqueive úmido sem revolvimento (Dutra et al., 2003). Portanto, o delineamento adotado foi inteiramente ao acaso com cinco tratamentos e seis repetições. Após 92 dias, procedeu-se à avaliação, pela extração e contagem dos nematóides do substrato e das raízes das plantas testadas. A análise estatística seguiu os mesmos procedimentos descritos para o experimento 1 .

\section{Experimento 4}

Utilizou-se como inóculo substrato infestado pela incorporação de raízes parasitadas pelo nematóide, conforme descrito no item substrato e inóculo. $\mathrm{O}$ efeito supressivo do sorgo granífero ' $\mathrm{C}$ ' e o milheto ' $\mathrm{BN} 2$ ', maus hospedeiros de $M$. javanica segundo os experimentos 1 e 2 e a literatura (Asmus \& Andrade, 1998), foi avaliado neste experimento tendo como termos de comparação C. spectabilis e alqueive úmido, ambos supressivos para $M$. javanica, e sorgo silageiro 'D' e milheto 'BRS 1501', estes bons hospedeiros segundo os experimentos 1 e 2 e a literatura (Inomoto et al., 2005). A semeadura foi direta em copos plásticos de $480 \mathrm{~cm}^{3}$ contendo $400 \mathrm{~cm}^{3}$ do substrato. No mesmo dia, oito amostras de 400 $\mathrm{cm}^{3}$ desse substrato foram utilizadas para a estimativa da população inicial do nematóide; esse material foi processado pelo método do peneiramento e centrifugação (Jenkins, 1964), para extração dos $J_{2}$. O experimento foi estabelecido no delineamento inteiramente ao acaso com seis tratamentos e quatro repetições; cada copo foi considerado uma repetição. Aos 79 dias após a semeadura, o nematóide foi extraído do substrato (Jenkins, 1964) e das raízes (Coolen \& D'Herde, 1972) e quantificado em lâmina de Peters sob microscópio óptico. A análise estatística seguiu os mesmos procedimentos descritos no experimento 1 .

\section{RESULTADOS}

No experimento 1 , os sorgos graníferos 'A', 'B' e ' $\mathrm{C}$ ' e o sorgo silageiro 'BRS 601' foram considerados maus hospedeiros de $M$. javanica, pois apresentaram FR menores que 1,0 e estatisticamente iguais aos de C. spectabilis (Tabela 1). Os demais sorgos silageiros, 'BRS 701', 'BRS 700' e 'D', foram considerados bons hospedeiros de $M$. javanica pelos elevados FR apresentados, embora menores que os da soja.

TABELA 1 - Fator de reprodução $(\mathrm{FR}=\mathrm{Pf} / \mathrm{Pi})$ de Meloidogyne javanica em sorgo silageiros (S) e graníferos (G), soja e Crotalaria spectabilis após 51-53 dias da inoculação com 3.000 ovos e $\mathrm{J}_{2}$ (experimento 1) e 77-80 dias da inoculação com 1.000 ovos e $\mathrm{J}_{2}$ (experimento 2 ), em casa de vegetação

\begin{tabular}{lccc}
\hline \hline Tratamentos & Tipos de sorgo & Experimento 1 & Experimento 2 \\
\hline Soja 'Pintado' & - & $86,07 \mathrm{a}$ & $159,61 \mathrm{a}$ \\
Soja 'Conquista' & - & - & $128,81 \mathrm{a}$ \\
IPA 7301011 & $\mathrm{S}$ & - & $28,47 \mathrm{~b}$ \\
BRS 701 & $\mathrm{S}$ & $19,90 \mathrm{~b}$ & $15,17 \mathrm{bcd}$ \\
BRS 700 & $\mathrm{S}$ & $18,55 \mathrm{~b}$ & $11,16 \mathrm{bcd}$ \\
Sorgo 'D' & $\mathrm{S}$ & $20,24 \mathrm{~b}$ & $10,16 \mathrm{bcd}$ \\
Dow 740 & $\mathrm{G}$ & - & $3,37 \mathrm{cde}$ \\
Dow 822 & $\mathrm{G}$ & - & $3,17 \mathrm{def}$ \\
Dow 741 & $\mathrm{G}$ & - & $1,38 \mathrm{ef}$ \\
Sorgo 'C' & $\mathrm{G}$ & $0,66 \mathrm{c}$ & $0,72 \mathrm{ef}$ \\
Sorgo 'A' & $\mathrm{G}$ & $0,53 \mathrm{c}$ & $0,43 \mathrm{ef}$ \\
Sorgo 'B' & $\mathrm{G}$ & $0,49 \mathrm{c}$ & $0,84 \mathrm{ef}$ \\
BR 304 & $\mathrm{G}$ & - & $0,67 \mathrm{ef}$ \\
BRS 601 & $\mathrm{S}$ & $0,10 \mathrm{c}$ & $0,05 \mathrm{f}$ \\
C. spectabilis 'Comum' & - & $0,02 \mathrm{c}$ & $0,00 \mathrm{f}$ \\
\hline
\end{tabular}

$\overline{\text { Valores são médias de cinco repetições. Médias seguidas pela mesma letra nas colunas }}$ não diferem significativamente entre si pelo teste de Tukey $(P=0,05)$. 
No experimento 2, os sorgos formaram três grupos conforme os FR apresentados: 1) bons hospedeiros de $M$. javanica, grupo composto pelos genótipos para silagem IPA 7301011, BRS 701, BRS 700 e D, caracterizados pelos FR elevados, acima de 10,$0 ; 2$ ) maus hospedeiros, grupo composto por BRS 601, BR 304, A, B e C, em sua maioria graníferos (exceção: BRS 601), caracterizados pelos FR menores que 1,0 e estatisticamente iguais aos de C. spectabilis; 3) hospedeiros moderadamente desfavoráveis a $M$. javanica, grupo formado pelos sorgos graníferos 'Dow 822', 'Dow 741' e 'Dow 740', caracterizados pelos FR intermediários entre os grupos 1 e 2 (Tabela 1). À semelhança do verificado no experimento 1 , nenhum dos sorgos apresentou FR comparáveis aos da soja.

No experimento 3, C.juncea e C.spectabilis reduziram a densidade do nematóide (Tabela 2), conforme relatos anteriores (Santos \& Ruano, 1987; Inomoto et al., 2006). Confirmou-se que o sorgo 'IPA 7301011' é bom hospedeiro de $M$. javanica, em acordo com resultados do experimento 2 e Inomoto et al. (2005). A maior reprodução do nematóide no referido genótipo $(\mathrm{FR}=24,45)$ em comparação ao milheto 'BRS 1501' ( $\mathrm{FR}=2,77)$ é outro resultado confirmatório, pois já verificado no mesmo trabalho citado.

No experimento 4 , a população inicial média no substrato foi de $682 \pm 278 \mathrm{~J}_{2}$ por copo. Os tratamentos foram classificados em três grupos segundo o FR ou o índice de sobrevivência: sorgo silageiro ' $D$ ' > milheto 'BRS 1501' $>$ C. spectabilis e alqueive úmido. Milheto 'BN 2' e sorgo granífero ' $\mathrm{C}$ ' apresentaram resposta intermediária entre a classe formada por milheto 'BRS 1501' e aquela de $C$. spectabilis e alqueive úmido (Tabela 3). Logo, os milhetos testados se mostraram próximos entre si, embora $\mathrm{BN} 2$ possa ser considerado hospedeiro menos favorável de $M$. javanica que BRS 1501, pois não diferiu de C. spectabilis e do alqueive úmido, além de ter repetido o valor de FR abaixo de 1,0 obtido anteriormente por Asmus \& Andrade (1998). Por outro lado, comprovou-se que os sorgos silageiros se diferenciam amplamente, em termos de reprodução de $M$. javanica, dos sorgos graníferos.

\section{DISCUSSÃO}

O sorgo granífero pode contribuir positivamente no manejo de $M$. javanica, pois os genótipos testados nos experimentos 1 e 2 se mostraram, em sua maioria, maus hospedeiros de $M$. javanica, em concordância com relatos dos Estados Unidos (Rich \& Kinloch, 2007a,b). Resposta inversa foi apresentada pelos sorgos silageiros, com exceção de BRS 601. Assim, como regra geral, os sorgos silageiros testados não devem ser utilizados em áreas infestadas por M.javanica.

No caso dos milhetos, embora a diferença entre os materiais testados, BRS 1501 e BN 2, não tenha sido significativa, há indícios suficientes para considerar BN 2 menos favorável que BRS 1501, devendo ser preferida em áreas sob SPD infestadas com $M$. javanica. Nesse
TABELA 2 - Fator de reprodução $(\mathrm{FR}=\mathrm{Pf} / \mathrm{Pi})$ de Meloidogyne javanica em sorgo, milheto e duas crotalárias após 92 dias de inoculação com 1.000 ovos e $\mathrm{J}_{2}$ em casa de vegetação. Em alqueive úmido, avaliou-se a sobrevivência dos nematóides após o mesmo período

\begin{tabular}{lcc}
\hline \hline Tratamentos & FR & Sobrevivência \\
\hline Sorgo 'IPA 7301011' & $24,45 \mathrm{a}$ & - \\
Milheto 'BRS 1501' & $2,77 \mathrm{~b}$ & - \\
C. juncea 'IAC-KR-1' & $0,21 \mathrm{c}$ & - \\
C. spectabilis 'Comum' & $0,33 \mathrm{c}$ & - \\
Alqueive úmido & - & 0,05 \\
\hline
\end{tabular}

Médias de seis repetições. Médias seguidas pela mesma letra na coluna não diferem significativamente entre si pelo teste de Tukey $(P=0,05)$.

TABELA 3 - Fator de reprodução (FR = Pf/Pi) de Meloidogyne javanica em dois sorgos, dois milhetos e Crotalaria spectabilis após 79 dias da semeadura em substrato contendo $682 \mathrm{~J}_{2}$. Em alqueive úmido, avaliou-se a sobrevivência dos nematóides após o mesmo período

\begin{tabular}{lcc}
\hline \hline Tratamentos & FR & Sobrevivência \\
\hline Sorgo 'D' & $42,15 \mathrm{a}$ & - \\
Milheto 'BRS 1501' & $3,31 \mathrm{~b}$ & - \\
Milheto 'BN 2' & $0,56 \mathrm{bc}$ & - \\
Sorgo 'C' & $0,50 \mathrm{bc}$ & - \\
C. spectabilis 'Comum' & $0,00 \mathrm{c}$ & - \\
Alqueive úmido & - & 0,00 \\
\hline
\end{tabular}

Valores são médias de quatro repetições. Médias seguidas pela mesma letra na coluna não diferem significativamente entre si pelo teste de Tukey $(P=0,05)$.

sentido, torna-se indispensável a identificação do genótipo do milheto, que é uma das principais culturas de cobertura atualmente utilizadas, com cerca de 4 milhões de hectares ocupados anualmente (Mingardo, 2005).

Comprovou-se ainda que $C$. juncea e principalmente C. spectabilis são eficientes supressoras de M. javanica. No Brasil, é pouco significativo o uso de crotalárias em rotação com culturas extensivas. Merece destaque, porém, seu efeito positivo na produtividade da soja, pela capacidade de melhorar as características físicas, químicas e biológicas do solo e reduzir a população de algumas espécies de nematóides (Tanaka et al., 1992). Menos freqüente ainda é seu uso como cultura de sucessão. Nesse caso, recomenda-se que as crotalárias antecedam a cultura de verão, sendo portanto semeadas no início de outubro e dessecadas (para sistema plantio direto) ou incorporadas (para plantio convencional) em fins de dezembro (Carvalho et al., 2004).

\section{AGRADECIMENTOS}

Os autores Mário Inomoto e Rosangela Silva agradecem ao Conselho Nacional de Desenvolvimento 
Científico e Tecnológico - CNPq e os autores Viviane Santos e Giovane Almeida à Fundação de Estudos Agrários "Luiz de Queiroz" - Fealq, pela concessão de bolsa de estudo.

\section{REFERÊNCIAS BIBLIOGRÁFICAS}

ASMUS GL, ANDRADE PJM (1998) Reprodução do Nematóide das Galhas em Plantas Forrageiras Utilizadas em Sistemas Integrados de Produção Agropecuária. Dourados MT. Embrapa Agropecuária Oeste. Boletim, 28.

CARVALHO MAC, ATHAYDE MLF, SORATTO RP, ALVES MC, ARF O (2004) Soja em sucessão a adubos verdes no sistema de plantio direto e convencional em solo de Cerrado. Pesquisa Agropecuária Brasileira 39:1141-1148.

CASTRO JMC, LIMA RD, CARNEIRO RMDG (2003) Variabilidade izoenzimática de populações de Meloidogyne spp. provenientes de regiões brasileiras produtoras de soja. Nematologia Brasileira 27:1-12.

COOLEN WA, D'HERDE CJ (1972) A Method for the Quantitative Extraction of Nematodes from Plant Tissue. Ghent. State Nematology and Entomology Research Station.

DUTRA MR, CAMPOS VP, TOYOTA M (2003) Manejo do solo e da irrigação para o controle de Meloidogyne javanica em alface. Nematologia Brasileira 27:29-34.

HARTMAN KM, SASSER JN (1985) Identification of Meloidogyne species on the basis of differential host test and perineal-pattern morphology. In: Barker KR, Carter CC, Sasser JN (Eds.) An advanced treatise on Meloidogyne: II. Methodology. Raleigh CN. Cooperative publication of the Department of Plant Pathology North Carolina State University and the United States Agency for International Development. pp. 69-77.

INOMOTO MM, ASMUS GL, FERRAZ MA, SAZAKI CSS, SCHIRMANN MR (2005) Reação de dez coberturas vegetais utilizadas no sistema plantio direto a Meloidogyne javanica. Summa Phytopathologica 31:367-370.

INOMOTO MM, MOTTA LCC, BELUTI DB, MACHADO ACZ (2006) Reação de seis adubos verdes a Meloidogyne javanica e a
Pratylenchus brachyurus. Nematologia Brasileira 30:39-44.

JENKINS WR (1964) A rapid centrifugal-flotation technique for separating nematodes from soil. Plant Disease Reporter 48:692.

KLEYNHANS KPN (1986) Useful new characters for the identification of four Meloidogyne species. Phytophylactica 18:9394.

MINGARDO M (2005) Plantio direto traz vantagens. Disponível em: $\quad<$ http://revistarural.com.br/Edicoes/2005/artigos/rev89 palhada.htm>. Acesso em: 19 mar. 2007.

RICH JR, KINLOCH RA (2007a) Sorghum Nematode Management. Gainesville. Institute of Food and Agricultural Sciences, University of Florida. Disponível em: $<\mathrm{http} / / /$ edis.ifas. ufl.edu/NG017>. Acesso em 7 fev. 2007a.

RICH JR, KINLOCH RA (2007b) Soybean Nematode Management. Gainesville FL. Institute of Food and Agricultural Sciences, University of Florida. Disponível em: $<\mathrm{http} / /$ edis.ifas. ufl.edu/NG018>. Acesso em 7 fev. 2007b.

SANTOS FG (2003) Cultivares de Sorgo. Sete Lagoas. Embrapa Milho e Sorgo.

SANTOS MA, RUANO O (1987) Reação de plantas usadas como adubos verdes a Meloidogyne incognita raça 3 e $M$. javanica. Nematologia Brasileira 11:184-197.

SILVA JFV (1998) Problemas fitossanitários da soja no Brasil com ênfase em fitonematóides. Anais, XXI Congresso Brasileiro de Nematologia, Maringá PR. pp. 16-20.

SILVA JFV, DIAS WP, MANSOTE U, GOMES J (2001) Produção de Grãos em Ambientes com Nematóides de Galhas. Londrina PR. Embrapa Centro Nacional de Pesquisa da Soja.

TANAKA RT, MASCARENHAS HAA, DIAS OS, CAMPIDELLI C, BULISANI EA (1992) Cultivo de soja após incorporação de adubo verde e orgânico. Pesquisa Agropecuária Brasileira 27:14771483.

TAYLOR AL, SASSER JN (1978) Biology, Identification and Control of Root-knot Nematodes (Meloidogyne Species). Raleigh. Cooperative publication of the Department of Plant Pathology North Caroline State University and the United States Agency for International Development.

WANG KH, SIPES BS, SCHMITT DP (2002) Crotalaria as a cover crop for nematode management: a review. Nematropica 32:35-57. 